\title{
Studies on Fruit Development in Pink and White types of Wax Apple (Syzygium samarangense Merr. \& Perry) in Goa, India
}

\author{
Priya Devi S., Shejal A. Porob and Thangam M. \\ Horticulture Section, ICAR Central Coastal Agricultural Research Institute, Goa - 403 402, India. \\ Email : priyaars@yahoo.com
}

\begin{abstract}
Fruit development studies were taken up in white and pink types of wax apple trees aging twelve years old at Goa, India. The study was initiated with the onset of flowering in November during the year 2018. After tagging the flowers on anthesis, samples were drawn periodically to record parameters like fruit weight, fruit volume, fruit length and diameter (upper, middle and lower), quality or biochemical parameters like total acids and sugars. Relative growth rate (RGR) was calculated for all parameters and graphs were generated. In both the types, fruit weight, fruit volume, fruit length and diameter increased in a sigmoidal pattern. The quality characters like TSS, total acids and total sugars also showed a sigmoidal pattern of increase whereas the increase in reducing sugars exhibited a double sigmoidal pattern of increase. It was evident from the curves that there was pronounced peak in growth rate between 21 and 28 days after anthesis for fruit weight, fruit volume, fruit length and diameter, in both pink and white types of wax apple.
\end{abstract}

Key words: Fruit development, Goa, Wax apple, White and Pink types

\section{INTRODUCTION}

Wax apples (Syzygium samarangense Merr. \& Perry) (syn. S. Javanicum Miq.; Eugenia javanica Lam. in part; E. alba Roxb.) are watery crunchy tropical fruits, found commonly in South East Asian countries like, Malaysia, Indonesia, Thailand etc. These fruit trees are called after many vernacular names like, samarang rose apple, djamboesemarang (Indonesia); jambuayerrhio (Malaya); pinijambu (Ceylon); jumrool, jamrul, or amrool (India); chompukao, or chompukio (Thailand); makopa (Philippines); cashu di Surinam, or Curacaoseappel (Curacao); wax jambu and water apple, generally. The tree is indigenous from Malaya to the Andaman and Nicobar Islands where there are wild trees in the coastal forests. It was introduced into the Philippines in prehistoric times and is widely grown throughout islands. It is common in Thailand, Cambodia, Laos, Vietnam and Taiwan, frequently cultivated in India and in Zanzibar and Pemba, but primarily as an ornamental in earlier days. But now, realizing the scope of the processing potentialities, progressive farmers, and agro-ecotourism units of coastal India are keen in cultivating such exotic fruits. The wax apple is extra-tropical, growing only at the lower altitudes-up to $4,000 \mathrm{ft}(1,220 \mathrm{~m})$ in India. The waxy fruit, usually light-red, sometimes greenish-white or cream-colored, is pear-shaped, narrow at the base, very broad, and flattened, indented and adorned with the 4 fleshy calyx lobes at the apex. The skin is very thin, the flesh, white, spongy, juicy, sub-acidic to sweet, with ild flavours. There may be 1 or 2 some what rounded seeds, or none. The fruits are reported to have total acids content varying from $0.6 \%$ to $0.9 \%$ and TSS from 5.6 to $12.8 \%$ (Moneruzzama et al. 2015 and Rosnah et al, 2012), It has been reported that, in Ceylon, the fruits are ripe from March to May; in India, the flowering spans from Nov-Dec to Mar-April and fruits are available from March to June. in Java, flowering occurs from April to June and fruiting from June to August (Morton 1987). In Tripura (North Eastern part of India), these trees flower in March-April and fruit in June-July (Sankaran et al, 2006). In West coast of India (Goa), the trees initiate to flower in October-November and give fruits in summer (i.e.) during Feb-April. The spans of flowering and fruiting overlap, due to continuous 
flushes of flowering in the tree. Even after the peak bearing and harvest in April, the trees put forth some flowers and yield few fruits in June, with the onset of South West Monsoons of India. The pattern of fruit development with respect to morphological and biochemical changes during the growth phase has not yet been studied systematically in this region. Therefore, this study was undertaken in order to study the growth and development of wax apple fruits right from anthesis to harvest.

The study was conducted in ICAR-Central Coastal Agricultural Research Institute, located at Old Goa, Goa, India. Well grown and yielding trees of white (variety Krystal Taiwan) and pink types (variety Pink) of Syzygium samarangense, those are twelve years old were selected for the study. The study was initiated in November, when the onset of flowering was noticed. The flower buds open in the morning hours. The freshly opened flower buds were tagged on the day of anthesis. During the fruit development, the samples of minimum ten fruits were drawn once in seven days for analyses. Likewise, the samples were drawn till the harvest stage. At every stage (i.e.) on $7,14,21,28,35,42,49,56,63$ and 70 DAA (days after anthesis) morpho-physical parameters like, fruit weight, fruit volume, fruit diameter (as the fruit is bell shaped, diameter readings were recorded in three places viz., upper, middle and lower designated as D1, D2 and D3 respectively in the graphs) and fruit length were recorded.Fruit weight was recorded using electronic balance; fruit volume was measured using water displacement method; diameter readings were measured using Vernier Caliper. Besides, biochemical parameters like, total acids (titration against $0.1 \mathrm{~N}$ $\mathrm{NaOH}$ using phenolphthalein indicator), total sugars (Phenol-Sulphuric acid method) and reducing sugars (Nelson-Somyogi method) were also estimated in every stage of development. TSS was observed using digital refractometer. Growth curves were generated using RGR values using the formula, $\mathrm{RGR}=(\ln 2-\ln 1) /$ (tn2-t1), where $\ln$ are natural logarithmic values of readings recorded at regular time intervals and $t$ represents the time taken (say seven days in this study)

Goa experiences monsoon season from June to September or mid-October. Only after the complete cessation of monsoons, do the wax apple trees start showing fruit buds on the branches. During the period of study, the flowering phase in the trees under study was recorded from mid-October to mid-February. The period taken from anthesis to harvest was 63 and 70 days in pink and white wax apple respectively. It has been reported that, the formation of flower buds does not mean early flowering in Syzygium samarangense. In the dry season, wax apple commonly flowers early or late and even protocols have been developed by Shu et al (1998) in Taiwan to trigger the flowering period depending upon the site of flower panicles appearance viz., leaf axils, shoot tip, new flush etc. Usually, shoot growth proceeds in flushes which are more or less synchronous, depending on the climate. There are definite flowering seasons, often two, sometimes three in a year, but the timing varies from year to year. Wax jambu commonly flowers early or late in the dry season; the flowers appear to be self-compatible and the fruit ripens 3040 days after anthesis (Orwa et al. 2009). He has also reported that, flowers fall on the ground in 2-3 days, leaving behind the tiny fruits to mature and ripen in about 2 months. In favourable conditions, a healthy tree can produce abundant fruits and has two fruiting seasons annually, May-September and November to March as reported from Kenya. When mature, the tree is considered a heavy bearer and can yield a crop of up to 700 fruits. Sankaran et al. (2006) have reported that the wax apple trees have two flushes of flowering during March-April and June-July under climatic conditions of North Eastern Hill region, especially in Tripura. Moneruzzaman et al. (2012a), have reported after a detailed study on different varieties of wax apple, that, 'Giant Green' cultivar had creamy white flower colour, 'Masammanis Pink' had white colour flower, while 'Jambumadu Red' had the creamy white to light yellow flower andthe number of days between anthesis and the harvest maturity (DAA) were as 41, 46, and 55 days for 'Masammanis Red', 'Jambumadu Red' and 'Giant Green' under Malaysia climatic conditions. It is observed that the pink or red types take shorter duration for attaining maturity, when compared to green or white types, which is in corroboration with the current study. In a different study Moneruzzaman et al. (2015) has reported that 'Masam Manis Pink' cultivar had the earliest fruit development and maturity approximately 38 days after anthesis followed by 'JambuMadu Red' cultivar with nearly 45 days. On the other hand, 'Giant Green' cultivar had late maturity with about 50 days to reach harvest stage from anthesis. It has been noted that Syzygium pycnanthum required 80-89 days 
after anthesis to attain harvest stage (Mudiana and Ariyanti, 2010).

In wax apple, variety 'Pink', the average fruit weight recorded seven DAA was $1.28 \mathrm{~g}$, whereas during harvest (70 DAA), it was recorded as $47.16 \mathrm{~g}$ .The $21^{\text {st }}$ day average fruit weight of $5.59 \mathrm{~g}$ spurted to $24.05 \mathrm{~g}$ on $28^{\text {th }}$ DAA. The fruit volume was negligible on 7 and 14 DAA and recorded a value of $2.55 \mathrm{cc}$ on $21^{\text {st }}$ DAA, however, increased to $22 \mathrm{cc}$ on 28 DAA, in a trend similar to increase in fruit weight. The fruits harvested 70 DAA recorded fruit volume of $46.60 \mathrm{cc}$.

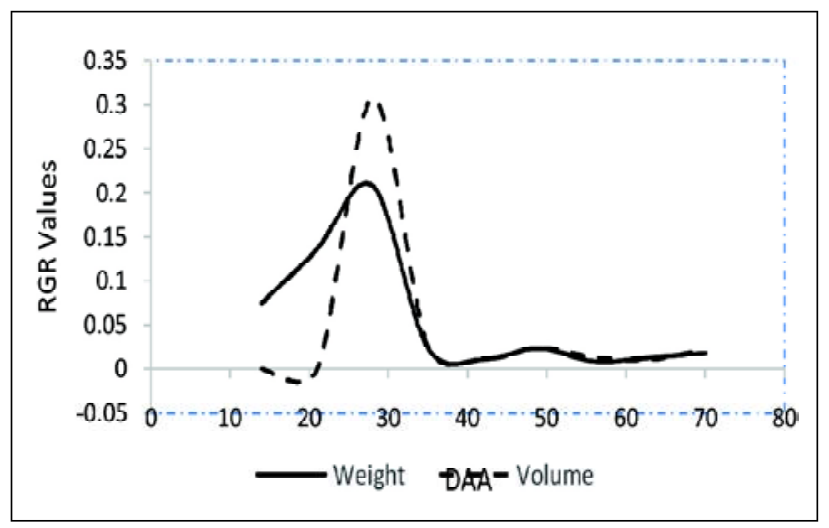

Fig. 1. RGR for fruit weight and volume in wax apple variety Pink

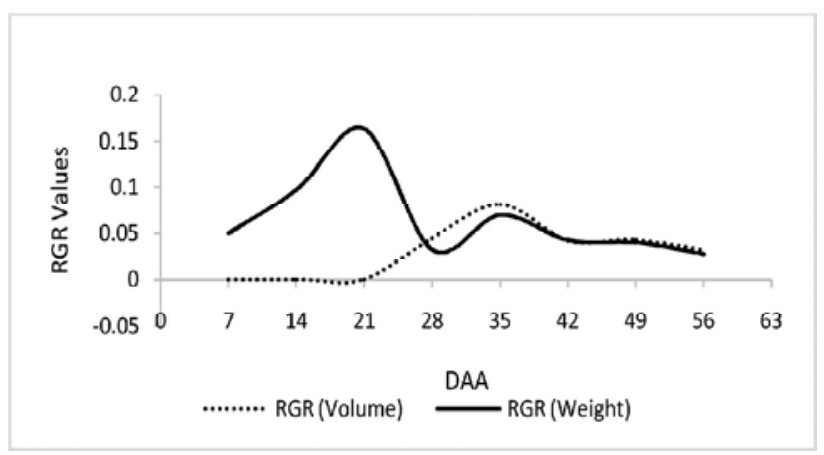

Fig. 2. RGR for fruit weight and volume in white wax apple variety Krystal Taiwan

The RGR curve (Fig 1) shows that there was a rapid development from $7^{\text {th }}$ to $35^{\text {th }}$ day and then, the growth rate slowed down towards the $49^{\text {th }}$ DAA, which later slightly increased (between 49 and 56 DAA) then decreased towards the harvest. The second increase recorded can't be considered as a peak, whereas the initial or first increase is definitely a peak, therefore depicting a sigmoid curve.

In white wax apple, variety 'Krystal Taiwan', the initial fruit weight was recorded to be $0.9 \mathrm{~g}$, which increased to $35.07 \mathrm{~g}$ during harvest, i.e., 63 DAA. The fruit volume values were negligible on 7, 14 and $21 \mathrm{DAA}$, whereas it was found to be $6.20 \mathrm{cc}$ on 28 DAA and increased to $34 \mathrm{cc}$ during harvest. The increase in fruit weight was steady from 7 to 21 DAA, and later on attained a jump size of $7.87 \mathrm{~g}$. The RGR curve pattern depicting the increase in fruit weight also showed a trend similar to that in Pink variety, expressing a well renowned peak 21 DAA and a less pronounced peak on $35^{\text {th }}$ DAA. The only peak in RGR curve for fruit volume in Krystal Taiwan, white wax apple coincided the second peak of fruit weight RGR curve (Fig. 2).

It has been reported by Moneruzzamanet al (2012 a) that, 'Giant Green' cultivar had the largest fruit (89 g) weight followed by 'Jambumadu Red' cultivar with a value of $85 \mathrm{~g}$ while 'Masammanis Pink' cultivar produced the minimum fruit $(78 \mathrm{~g})$ weight. In another study by Moneruzzaman et al (2012 b), the Pink variety wax apples recorded fruit weight of $38 \mathrm{~g}$. In a study conducted on different types of wax apples it was found that, the fruit weight varied significantly among 5 accessions of wax apples, ranging from $50.88 \mathrm{~g}$ in thered or dark pink type to $28.35 \mathrm{~g}$ in the light pink bell shaped type with a mean value of $35.66 \mathrm{~g}$ (Risvy, 2013). The fruit weight values recorded in the study are in corroboration with these reports.

The related species guava also showed a sigmoidal growth pattern, with one peak flanked by two slag phases (Mukherjee and Datta, 1967), whereas Salunkhe and Desai (1984) have reported in guava a sigmoidal growth pattern but with an unusual behaviour of rapid increase in fruit weight in the initial phase. Another fruit species Eugenia stipata (Hernandez et al. 2007) from the same family Myrtaceae also showed single sigmoidal growth pattern similar to the current study. Similarly, the growth curve of Pomegranate also showed a single sigmoidal pattern (Shulman, 1984).

In Pink variety wax apple, the average initial length seven DAA was observed to be $1.50 \mathrm{~cm}$, which increased to $6.60 \mathrm{~cm}$ during harvest stage ie.,70 DAA. The fruit equatorial diameter was measured upper side (D1), middle (D2) and lower side (D3), as the fruit is nearly pear shaped. D1 was $0.40 \mathrm{~cm}$ seven DAA and increased to $2.80 \mathrm{~cm} 70$ DAA. However, the increase was from 1.03 to $4.00 \mathrm{~cm}$ and 
1.38 to $4.20 \mathrm{~cm}$ for D2 and D3 respectively from 7 to $70 \mathrm{DAA}$. The fruit length increased from $1.50 \mathrm{~cm}$ to $6.60 \mathrm{~cm}$ during the development. Similar previous studies also show that, fruits are pear-shaped and 1.52 inches long(Orwaet al. 2009). 'Giant Green' and 'Masammanis Pink' cultivars had bell shaped fruits while 'Jambumadu Red' cultivar had a pear shaped fruit. (Moneruzzamanet al, 2012 a). Fruit length was $5.23 \mathrm{~cm}$ in Pink variety wax apple and fruit diameter was nearly 3.5 cmduring harvest. (Moneruzzamanet al, 2012 b)

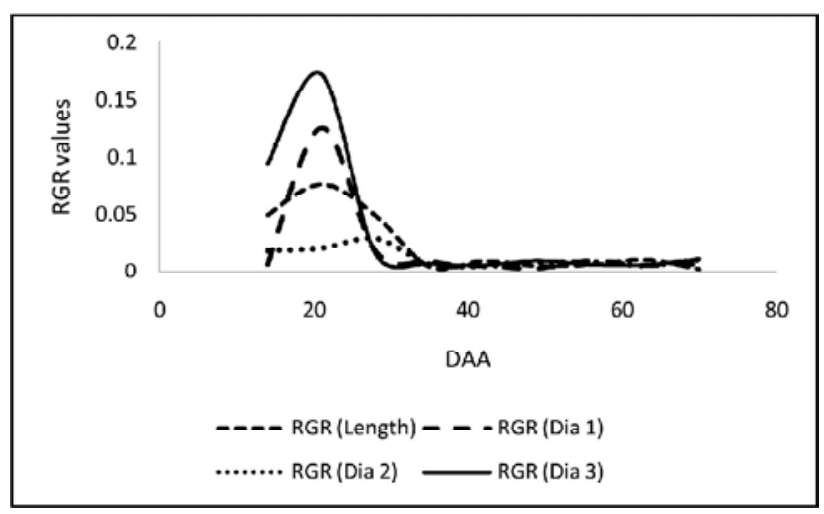

Fig. 3. RGR for fruit dimension parameters in wax apple variety 'Pink'

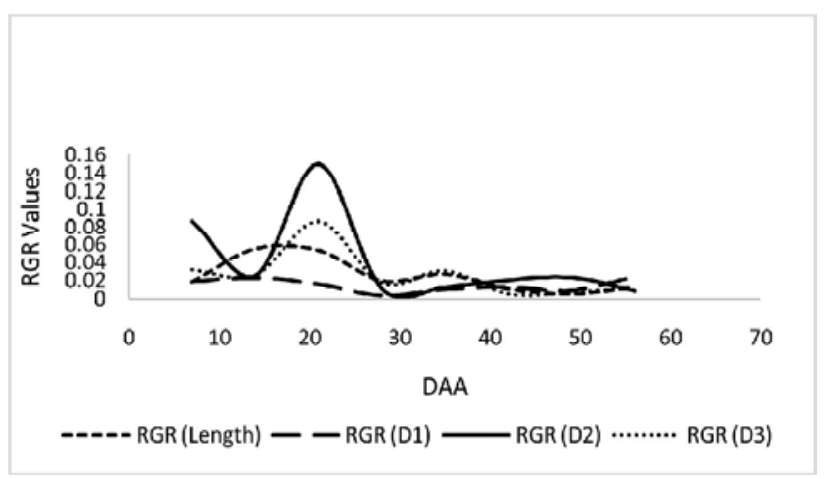

Fig. 4. RGR for fruit dimension parameters in white wax apple, variety Krystal Taiwan

The RGR curve shows that, there were pronounced peaks during increase in the polar and equatorial diameter (D1 and D3)between 21 and 28 DAA. But, the peaks in RGR curves of fruit weight and fruit diameter D2 occur between 28 and 35 DAA.Therefore, it can be concluded that the fruit growth follows a single sigmoid growth curve in wax apple variety 'Pink'. (Fig. 3)

In white wax apple, variety 'Krystal Taiwan', the initial average length seven DAA was $1.10 \mathrm{~cm}$, which increased to $4.60 \mathrm{~cm}$ on $63^{\text {rd }}$ DAA. D1, D2 and D3 were $0.40,1.00 \mathrm{~cm}$ and $1.23 \mathrm{~cm}$ respectively seven DAA and increased to $2.85,4.25$ and $4.60 \mathrm{~cm}$ during harvest i.e., 63 DAA.There was a single prominent peak noticed in the RGR curves for D2 and D3 during fruit development between 21 and 28 DAA.However, RGR for D3 showed a less prominent peak, coinciding with second less dominant peak in RGR curve for fruit length. The increase of length showed two peaks during 7-14 DAA and 35-42 DAA. (Fig 4)

In general, fruit size is a genetic characteristic of the cultivars and is also used for identification of cultivars. Previous studies show that the fruit of 'Jambumadu Red' cultivar was the longest $(8.2 \mathrm{~cm})$ followed by 'Giant Green' cultivar with a fruit length of $6.3 \mathrm{~cm}$, whilst least fruit length was observed in 'Masammanis Pink' cultivar with a value of $5.5 \mathrm{~cm}$. Fruit size is an inherent factor associated with different cultivars. 'Masammanis Pink' cultivar had the highest $(5.5 \mathrm{~cm})$ fruit diameter while, 'Jambumadu Red' cultivar fruit had the least $(4.6 \mathrm{~cm})$ diameter and 'Giant green' cultivar was intermediate at about 5.2 $\mathrm{cm}$. They also found that the number of cells per fruit was higher for large fruited cultivars than for small fruited cultivars (Moneruzzaman et al. 2012b). In the evaluation study on different cultivars of wax apples conducted by Risvy (2013), it was noticed that the length of observed fruits varied significantly and ranged from $7.04 \mathrm{~cm}$ to $4.23 \mathrm{~cm}$, with a mean value of $4.92 \mathrm{~cm}$. Similarly, the diameter also varied from $4.23 \mathrm{~cm}$ to $2.67 \mathrm{~cm}$, with a mean of $3.09 \mathrm{~cm}$. These values are in corroboration with the current study.

The length of wax apples increased from 1.5 to 5 $\mathrm{cm}$, the width from 1.2 to $6 \mathrm{~cm}$, fruit weight from 2 to $150 \mathrm{~g}$ during 80 days growing period from anthesis, all following a single sigmoidal growth pattern as reported by Shu et al (1998)

Wax apples, both pink and white are majorly composed of moisture, sugars and acids. They are crunchy, sweet and relishing for table purpose. In South East Asian countries, various products likejam, jelly, candy, syrup, flakes etc are prepared from these fruits. The mild sugar acid blend renders the fruits suitable for value addition. The immature fruits are mildly acrid and acidic and towards maturity, the acidity decreases and sugar concentration increases.

In Pink variety, the percentage of total titrable acids decreased from 0.42 (7 DAA) to 0.11 per centduring 
harvest. The rate of decrease in total acids touched a lowest peak 28 to $35 \mathrm{DAA}$ and after being stable for one more week, it steadily decreased till harvest stage (70 DAA).In white wax apple, the total titrable acids reduced from 1.43 per cent ( 7 DAA) to 0.19 per cent (63 DAA) during harvest. The RGR curve showed that, the decrease in acidity was steady and uniform from seven to $35 \mathrm{DAA}$, whereas, it reached a negative peak during 35-42 DAA, again followed by a steady decline in acidity percentage till harvest, therefore, depicting a single sigmoidal pattern (Fig 5). In similar studies, it was reported that the decrease in fruit acidity coincided with an increase in sugar content of the fruits. The lowest amount of titrable acidity $(0.78 \%)$ was observed in the 'JambuMadu Red' cultivar, followed by 'Giant Green' $(0.83 \%)$ and 'Masam Manis Pink' (0.90\%). It has also been recorded that the soluble solids content in 'JambuMadu Red' was wide-ranging from 5.63 to 12.5\% Brix (Moneruzzaman et al, 2015). In a different study, Moneruzzaman et al (2012 c) reported that titrable acidity of wax apple was $0.78 \%$. While comparing chemical composition changes in two types of wax apples, Rosnahet al (2012) found that, the total acidity of Kristal Taiwan (green white type) ranged between $0.2-0.25 \%$, while the total acidity of Semarang Rose (pink type) were between 0.07-0.1\%. These results are in corroboration with the results of this study.

In pink variety, Total Soluble Solids (TSS) increased gradually from 5.10 to $13.90^{\circ}$ Brix (7 to $70 \mathrm{DAA}$ ). The increase rate was gradual from 7 to 35 DAA, and then, there was a spurt in increase from 35 to 49 DAA. Later on, the raise in TSS was gradual up to 60 DAA and then, there was a sharp increase towards harvest.In white wax apple, TSS increased from 4.1 (seven DAA) to $15.6^{\circ}$ Brix during harvest (63 DAA). The rate of increase has a peak value during 35 to 42 DAA, coinciding the negative peak of reduction in acidity during fruit development. Therefore, it was observed that during fruit development, the significant increase in sugars and significant decrease in acids occur from 35 to 42 DAA. The abovementioned peak for increase in TSS was flanked by one less prominent peak during initial period of development i.e., 14-21 DAA and the other one towards the harvest stage i.e., 56-63 DAA (Fig 6). It has been noted by Orwa et al (2009) that, of the different types of wax apples, the reddest fruits are the sweetest and superior varieties of excellent quality available. Total soluble solids (TSS) percentage significantly varied and ranged from $10.39 \%$ to $13.96 \%$ with the mean value of $12.05 \%$ in five different types of wax apples evaluated in Bangladesh (Risvy, 2013). On comparing a green and Pink type, Rosnahet al (2012) has reported the total soluble solid (TSS) in Kristal Taiwan (5.9-9. $6^{\circ}$ Brix) and Semarang Rose (5.2-9.0 $0^{\circ}$ Brix). Moneruzzaman et al. (2012 b) have reported that pink wax apples have $5.6^{\circ}$ Brix TSS and $3.63 \mathrm{mg} / 10 \mathrm{~g}$ of total sugars.

In the present study, the total sugars content in Pink variety wax apple increased from 2.11 (7 DAA) to 5.95 (70 DAA) in a gradual manner. However, the RGR curve showed a peak in increase in total sugars,49-56 DAA followed by a sharp decline in rate and then a final spurt in the concentration of total sugars towards harvest stage (70 DAA) in a trend similar to that of increase in TSS content of the fruit. The concentration of reducing sugars in the fruit increased from $0.18 \%$ (seven DAA) to $1.98 \%$ (70 DAA). The trend in increase of reducing sugars also had an initial peak during 35 to 42 DAA, followed by a second peak during 49-56 DAA, thus showing a double sigmoid curve (Fig 6).

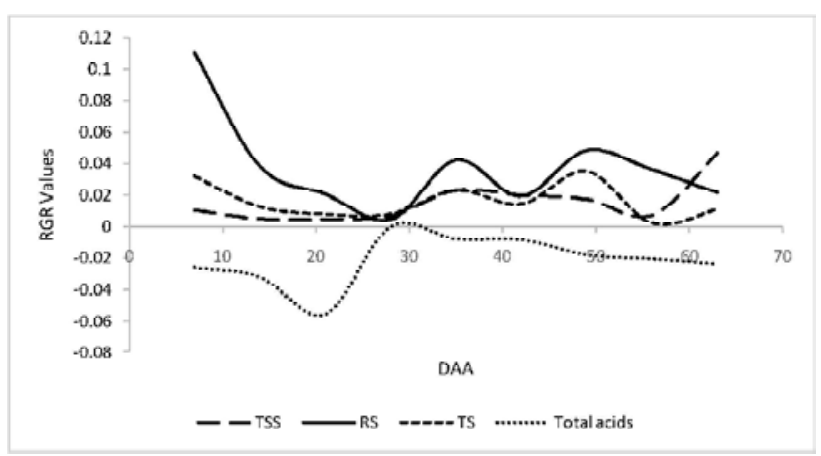

Fig. 5. RGR for quality characters in wax apple variety 'Pink'

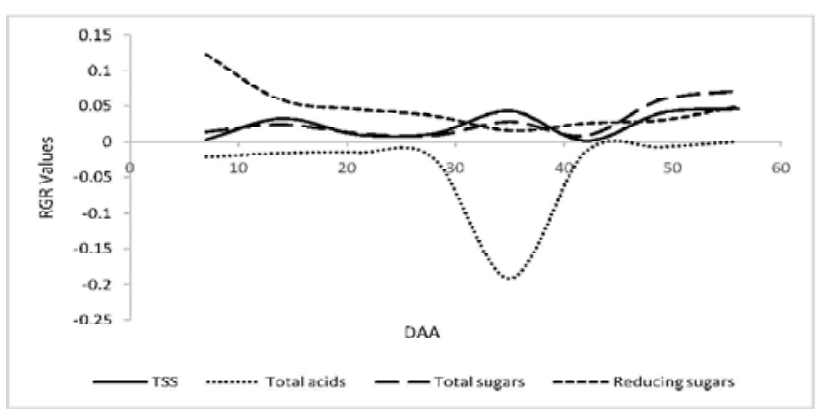

Fig. 6. RGR for quality characters in 'white' wax apple variety Krystal Taiwan 
In white wax apple variety Krystal Taiwan, total sugars content in fruit increased from 2.8 per cent (seven DAA) to 13.87 per cent (63 DAA) at harvest. The rate of increase in total sugars showed a trend just similar to that of TSS with a peak during 35 to 42 DAA, flanked by one less prominent peak during initial period of development i.e., 14-21 DAA and the other one towards the harvest stage i.e., 56-63 DAA. The reducing sugars in the white wax apple fruits increased from 0.62 per cent (seven DAA) to 9.27 per cent (63 DAA) at harvest. The RGR curve showed that the trend in rate of increase in reducing sugars was stable without any peak, except during the initial period i.e., seven to 14 DAA.

In a study on compositional changes in two cultivars of wax apple in Malaysia, it was found that, the fructose content was highest in the water apple juice in the range of 7.05 to $9.15 \%$ (Kristal Taiwan) and 4.77 to $9.25 \%$ (Semarang Rose) indicating that, the fructose content is the major sugar contributing to water apple sweetness followed by glucose and sucrose. The glucose content varied between 6.74 to $8.37 \%$ (Kristal Taiwan) and 3.53 to $8.26 \%$ (Semarang Rose) while the sucrose content varied between 0.19 to $0.36 \%$ (Kristal Taiwan) and 0.38 to $1.51 \%$ (Semarang Rose). Fructose, being sweeter than sucrose and glucose, has a desirable influence on the taste of fruits. (Rosnah et al, 2012)

Sugar concentration of the fruit increased with fruit growth with fructose and glucose as the main components; starch content reached a maximum value of $11 \%$ and decreased towards ripening (Shu et al, 1998).

Similarly, in pomegranate fruit development, a significant increase in TSS, total sugars and reducing sugars was observed 80 DAA, with a maximum values on 140 DAA. The equilibrium concentration of these biochemical on 100 DAA mark optimum maturity and the further increase is during phase of ripening (Kulkarni and Aradhya, 2005). Likewise, in both types of wax apples studied, there was a peak in increase of sugars between 30 and 40 DAA and then after 50 DAA.

This systematic study, conducted in Syzygium samarangense (pink and white types) indicates that the fruit development, comprising various aspects of the fruit follow sigmoid and double sigmoid growth pattern, which is in corroboration with similar studies conducted in fruits like wax apples in different places like Malaysia, Taiwan and Bangladesh and also in strawberry and apple.

\section{REFERENCES}

Hernández, M.S., Martínez O., Fernández-Trujillo J.P. 2007. Behaviour of arazá (Eugenia stipitata Mc Vaugh) fruit quality traits during growth, development and ripening. Scientia Horticulturae. 111(3):220-227

Kulkarni A,P., Aradhya S.M. 2005. Chemical changes and antioxidant activity inpomegranate arils during fruit development. Food Chemistry. 95: 319-324

Moneruzzaman K.M., Alebidi A.I. and Al-Saif A.M. 2012a. Assessment of genetic diversity in three cultivars of Syzygium samarangense grown in Malaysia by using Morphological and physiological parameters. Res. J. Biotech. 7(3):16-22

Moneruzzaman K,M., Alebidi A.I., Hossain A.S., Boyce. 2015. Physiological and biochemical properties of three cultivars of wax apple (Syzygium samarangense [Blume] Merrill \&
L.M. Perry) fruits. J. Sustain. Sci. Manage. 10(1): 66-75

Moneruzzaman,K,M., Boyce A.N., Normaniza Osman and Sharif Hossain ABM. 2012 c. Physiochemical and phytochemical properties of wax apple (Syzygium samarangense [Blume] Merrill \& L. M. Perry var. JambuMadu) as affected by growth regulator application. The Scientific World Journal. (728613). p13

Moneruzzaman K.M., Osman N., Hossain A.S. and Boyce A.N. 2012b. Effects of the Phloemic Stress on the Growth, Development and Quality of Wax Apple (Syzygium samarangense) cv. Jambumadu. Sains Malaysiana 41(5):553-560

Morton, J. 1987. Java Apple. InJulia F. Morton (ed.). Fruits of warm climates. Miami, FL. p. 381-382.

Mudiana and Ariyanti.2010. Flower and fruit development of Syzygium pycnanthumMerr. \& L.M. Perry. Bio Diversitas. 11(3): 124-128 
Mukherjee,S,K. and M.N.Dutta.1967.Physicochemical changes in Indian guava (Psidiumguajava L.) during fruit development. Curr Sci. 36: 675-76.

Orwa, C., A.Mutua, R.Kindt, R.Jamnadass and Anthony, S.2009. Agroforestree Database: a tree reference and selection guide version 4.0. World Agroforestry Centre, Kenya

Risvy.A. 2013. Morphological and Molecular Characterization of Wax Jambu (Syzygium samarangense). M.Sc., diss., Department of Horticulture, Bangladesh Agricultural University, Mymensingh

Rosnah, S., W.K.Wong, M.Noraziah, and H.Osman. 2012. Chemical composition changes of two water apple (Syzygium samarangense). International Food Research Journal 19(1): 167-174
Salunakhe, D. K. and B.B.Desai. 1984. Postharvest Biotechnology of Fruits. Vol. 2. Guava. Boca Raton, Florida. CRC. Press, Inc., USA, 148 pp.

Sankaran, M., Jai Prakash, N.P. Singh, A.Sukhlabaidya. 2006. Wild edible fruits of Tripura. Natural Product Radiance. 5(4):302305

Shu, Z.H., S.C.Liaw, H.L.Lin, K.C.Lee.1998. Physical characteristics and organic compositional changes in developing wax apple fruits. Journal of the Chinese Society for Horticultural Science. 44:491-501

Shulman,Y., L.Fainberstein. andLavee, S.. 1984. Pomegranate fruit development of maturation. Journal of Horticultural Science, 59 (2): 265-2740

(Received on 30.07.2019 and accepted on 12.12.2019) 